\title{
Mixed methods research for the novice researcher
}

\section{ABSTRACT \\ KEY WORDS \\ mixed methods; qualitative research; quantitative research; paradigms; postpositivism}

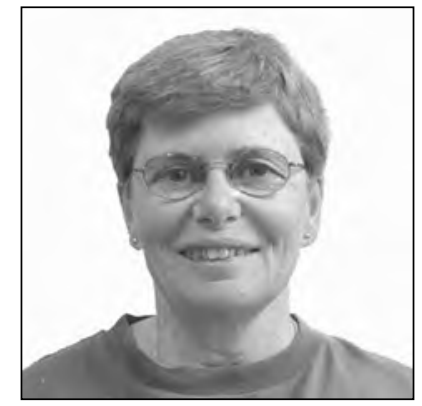

LYNNE S GIDDINGS

Associate Professor School of Nursing Auckland University of Technology Auckland, Aotearoa New Zealand

\section{INTRODUCTION: \\ ANYTHING GOES?}

$A^{t}$ first glance, mixed methods appears to offer an 'anything goes' approach to research. Not so. There is always a taken-forgranted, and usually unacknowledged, worldview with underlying assumptions that guides the choice of methods to be mixed and how the data will be used. If this worldview or paradigm is not made explicit during the research process, a researcher may find themselves lost,

\section{Accepted 27 July 2006}

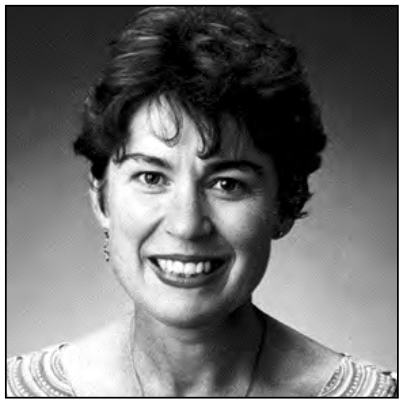

BARBARA M GRANT

Senior Lecturer

Centre for

Professional

Development

The University of

Auckland

Auckland, Aotearoa

New Zealand

either unable to answer the research question or trying to push contradictory data into a compromising fit. In our experience, health and social science students undertaking research for the first time often struggle with the inevitable complexities and messiness of the research design process. Yet the choices we make about methods are important because particular methods will close down or open up research possibilities in quite distinctive ways; they will allow some questions to be explored but not

Volume 23, Issue 1, October 2006

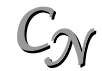


others. When undertaking a mixed methods study careful consideration needs to be given to the assumptions underpinning the research approach so there is congruence between the chosen methods and the research question. A fundamental assumption underpinning this article is that mixed methods is a research tool rather than a methodology in its own right.

\section{A researcher's worldview or paradigm}

In this paper we focus on the most commonly used approach to mixed methods research, a combination of qualitative and quantitative methods for collecting and analysing data underpinned by postpositivist assumptions. We view postpositivism as an extension of the traditional scientific worldview or paradigm known as positivism (as we will shortly explain). In our view (described in detail in Grant \& Giddings, 2002), the main health and social science research paradigms are four: the positivist/scientific, interpretivist/constructivist, radical/critical and poststructural. A researcher's paradigm reflects their beliefs about what reality is (ontology), what counts as knowledge (epistemology), how one gains knowledge (methodology), and the values one holds (axiology). The first three terms may be scarily familiar to you but the last is likely to be new. Yet the axiological positioning of a researcher is often the determining factor in the research decision-making process. For instance, a person who has strong values on issues of social justice and equity is likely to be drawn to the radical/critical paradigm because it focuses on social action and social change. The emergence of Kaupapa Maori research (indigenous within Aotearoa New Zealand) may be understood in part as driven by profound axiological differences embedded in different cultures. Taken together, paradigm assumptions and beliefs indicate the proper kind of researcher-researched relationship. Importantly, paradigms are incommensurate, that is you cannot easily work across them (for instance by combining methodologies from different paradigms) without getting into contradiction.

We argue that postpositivism is a shift from within the positivist paradigm. It developed during the 1960s, largely from the increasing recognition without and within science of the ideological and practical limitations of certain designs and strategies. The prefix 'post', when attached to words like positivism, modernism, and colonialism for example, indicates a further development of the original concept, but one that is fundamentally critical of it. So postpositivism continues most of the key philosophical assumptions of positivism but in a changed or more moderate form. For example, a core fundamental positivist assumption is that of determinism, the belief that effects have a determinable cause and actions have predictable outcomes. Postpositivists maintain this assumption in a modified form: rather than assuming a linear process of cause and effect, they perceive outcomes as the result of a complex array of causative factors that interact with each other. Mixed methods researchers are not always aware of the postpositivist underpinning of their studies. By omission, their work may reflect an assumption of being paradigm free or they may make unsupported claims of creating the 'best of both worlds' by incorporating other paradigms such as interpretive or radical/critical. One of us has described such mixed methods studies as 'positivism dressed in drag' (Giddings 2005: 195).

In what follows we begin by clarifying the terms methodology/methods and qualitative/ quantitative. We then offer some guidelines on how to decide when to use a mixed methods design, followed by a description of the various designs we consider most useful in health research. Illustrative examples from nursing research studies and references for further reading are provided along the way. Although mixed methods research is largely located in postpositivism, we suggest that it can be used by researchers situated within other paradigms. 


\section{WHAT IS 'MIXED' IN MIXED METHODS RESEARCH?}

There is some debate over whether or not mixed methods research is itself a research paradigm or methodology. In our view, the most commonly used mixed methods designs are simply an approach to research that mixes qualitative and quantitative methods. To understand this, it is helpful to be clear about the difference between methodology and methods, and the terms qualitative and quantitative.

Methodology is a more abstract term than methods and refers to the theoretical assumptions and principles that underpin a particular research approach. It guides how a researcher frames the research question and decides on what process and methods to use. Methods, in contrast, are much more concrete and practical - they are the tools for collecting and analysing data. The methods a researcher chooses need to fit with the research question. For example, if your research question was 'what is it like for someone to have a blood test?' (their experience), but then you focused your study on the results of the blood tests (measurements) or how the blood specimens were taken (observations of technique), there would be a lack of fit. The data you gathered would not allow you to address the research question.

The terms quantitative and qualitative are commonly used to describe both the methods and the methodologies used in health research. Confusing? Yes! Historically, quantitative research has been viewed as synonymous with positivism and qualitative with interpretivism - hence the association with methodology. Some writers consider the terms to refer to two research paradigms in and of themselves (Blaxter et al. 2001) or, at the other extreme, as terms to merely describe forms of data: quantitative data being numbers and statistics, and qualitative being words and narratives. We argue that the two terms most usefully describe different 'types of methods' (Guba \& Lincoln 1994: 105) that may be used for data collection and analysis.
In this sense the methods are 'a-theoretical and a-methodological' (Sarantakos 1998: 34) and therefore can be mixed. Taking the blood testing example above, the researcher could use the data collection methods of interviewing the participants, measuring blood test results, and observing procedure, depending on their question. To decide sensibly, the researcher would have to identify their research question first.

\section{DECIDING TO USE MIXED METHODS RESEARCH}

Mixed methods research has a range of strengths. It is particularly useful in survey, evaluation, and field research (Patton 2002) because it has a broader focus than single method design and gathers more information in different modes about a phenomenon. It can also give insight into complex social phenomena such as family violence or anorexia nervosa by producing findings that illuminate that complexity. Yet another strength of mixed methods design is that the breadth of findings can bring value to the research process itself by highlighting the particular shortcomings in each of the methods used and compensating for them. When the findings are contradictory, they can reveal researcher assumptions that would not otherwise have been known or the constraints and biases of ways of measuring or interpreting something (refer to Exemplar 1 below for an example of this). However, what makes this design most attractive to health practitioners is its pragmatism, that is, its usefulness in the clinical setting to collect comprehensive information about a phenomenon that can then guide decisions about practice. Examples of such phenomena include: hospital admission and discharge procedures; introduction of new processes, procedures or techniques; and the responses of clients to being asked about violence in their lives when attending an accident and emergency or health clinic.

All research approaches have their limitations - so too mixed methods. Generally this design

Volume 23, Issue 1, October 2006 
takes more time, both at the beginning for preplanning and negotiation (because of the mix of researcher skills needed) and at the end for coming to agreement as to how the findings fit together (or not) and what they ultimately mean. For these reasons, we suggest graduate students - especially in masters by research programmes - approach the use of mixed methods with caution. However, its usefulness is such that it may be the best design to answer your question. We suggest if you decide to carry out a mixed methods study that you find a sponsor or a community of practice with others undertaking the same research approach. Make sure as well that your supervisor is supportive of this approach and, even better, experienced with using it.

As noted earlier, most mixed methods research reflects postpositivist assumptions. Mixed methods research, however, is certainly not confined to this paradigm. It can be located within others. For example, feminist researchers have long shown creative flexibility in their approaches to collecting and analysing data, able to utilise quantitative methods in the service of radical/critical or poststructuralist paradigms.

Deciding where to locate your mixed methods research is a process requiring some thought - and probably discussion with others. Here are some questions that can guide your thinking, writing, reading and talking at this time:

1. What is your issue/problem and what do you want to know about it? (This is your research question and you may refine it over time as you collect and analyse data.)

2. What is your personal research orientation: what values, attributes, abilities, and research skills do you bring to the study?

3. What are the dominant research traditions in your academic discipline/s?

4. What methods best suit your research purpose (aim or objective) and context (institutional, social, cultural, political)?

5. Which method is going to be the primary data gatherer? Would a quantitative or a qualitative method collect the most pertinent data? This decision and the way you decide to analyse your data are most likely to reveal the underpinning research paradigm that will guide the research process.

6. How does the secondary data collection method complement the primary? What does it contribute to the purpose of your study?

7. How will you sequence the methods? What needs to be known first?

8. Do you have the skills to collect and analyse both data sets? Do you need to consult a methodological expert or include a coresearcher to complement your skills?

9. How much time do you have to carry out this study? (This is very relevant for research students who often have a very limited time-frame.)

Once you have answered these questions, you will have thought through most of the issues that bear on how you will carry out your mixed methods study. You will have begun to realise that you may not have a free choice in this matter - that strong personal preferences (yours but also your supervisor's), as well as perhaps even pressures from your clinical practice area, all have to be dealt with.

\section{MAIN DESIGNS OF MIXED METHODS RESEARCH}

Various typologies have been developed to help understand the many design possibilities in mixed methods research (Creswell 2003; Morse 1991; Tashakkori \& Teddlie 1998). The one offered here in Table 1 is based on those but departs from them too. In our typology (as in Creswell 2003) there are two main designs: sequential $(\rightarrow)$ and concurrent $(+)$. We have abbreviated quantitative to QUANT or quant and qualitative to QUAL or qual.

\section{Sequential mixed methods designs}

In sequential designs, one method is used first, 
Table 1: Typology of Mixed Methods Research Designs (derived from Creswell 2003)

\begin{tabular}{lll} 
& Sequential & Concurrent \\
Equal & QUAL $\rightarrow$ QUANT & QUANT + QUAL \\
Unequal & QUANT $\rightarrow$ QUAL & QUAL + QUANT \\
& QUAL $\rightarrow$ quant & QUAL + quant \\
& qual $\rightarrow$ QUANT & qual + QUANT \\
& QUANT $\rightarrow$ qual & QUANT + qual \\
& quant $\rightarrow$ QUAL & Quant + QUAL \\
\hline
\end{tabular}

followed then by the other: QUANT $\rightarrow$ QUAL or QUAL $\rightarrow$ QUANT. In the analysis and interpretation phase, the data may be treated equally (as suggested by the notation above) or one set of data may be seen as secondary as suggested by use of lower-case letters in these notations: QUANT $\rightarrow$ qual, quant $\rightarrow$ QUAL, QUAL $\rightarrow$ quant, or qual $\rightarrow$ QUANT. We have chosen as our exemplars two QUANT $\rightarrow$ QUAL studies to show the variety of ways such studies can be designed, and one QUANT $\rightarrow$ qual study. The last combination is one of the more commonly used sequential designs in health and social science research. Nursing research articles are used for the exemplars.

\section{Sequential exemplar 1 \\ QUANT $\rightarrow$ QUAL (integrated), summarised in Table 2}

Pamela Ironside's (2003) title Trying something new: Implementing and evaluating narrative pedagogy using a multimethod approach, clearly flags that more than one method was used in her evaluative study. Ironside used a pretest-posttest questionnaire followed by semi-structured interviews to gather data from her students. It is not until the presentation of the findings that it is clear that a sequential mixed methods design was used, with the data from both methods treated equally (QUANT $\rightarrow$ QUAL): Ironside first sets out the student responses to various items on the questionnaire giving some of the statistical results in support of conclusions made. The qualitative data are then presented thematically. In her analysis she attempts to integrate the findings from the two data sources. The quantitative findings were in a number of instances incongruent and inconsistent with the qualitative findings. Most of the discussion in the article arises from the mismatch between these findings. This outcome of a mixed methods study is one of its strengths. New questions are posed and new ways to explore them become possible.

\section{Sequential exemplar 2}

$$
\begin{gathered}
\text { QUANT } \rightarrow \text { QUAL (separated), } \\
\text { summarised in Table } 3
\end{gathered}
$$

In contrast to Ironside's work, Jane KoziolMcLain and colleagues (2004) used a sequential

TAble 2: Sequential Exemplar 1: QUANT $\rightarrow$ QUAL (Integrated)

\begin{tabular}{ll} 
Ironside (2003) & $\begin{array}{l}\text { Trying something new: Implementing and evaluating narrative pedagogy } \\
\text { using a multimethod approach }\end{array}$ \\
\hline Design & Pretest - posttest questionnaire followed by semi-structured interviews were \\
Comment & used to gather data from her students. \\
& - Attempts to integrate the findings from both data sources. \\
\hline
\end{tabular}


Table 3: Sequential Exemplar 2: QuANT $\rightarrow$ QUal (Separated)

\begin{tabular}{ll} 
Koziol-McLain & Prevalence of intimate partner violence among women presenting \\
et al. (2004) & to an urban adult and paediatric emergency care department \\
Design & - First a questionnaire, followed by a semi-structured telephone interview with a sub-sample. \\
Comment & - Shared primary objective but different research questions and different primary investigators. \\
& $\begin{array}{l}\text { - Both parts of study treated equally but separately with the findings presented as stand-alone } \\
\text { studies and published in different journals. }\end{array}$ \\
\hline
\end{tabular}

design but separated the quantitative and qualitative parts of their study. They researched the topic of addressing family violence in the healthcare setting and described their design as mixed methods. There was one research team, one ethics proposal, and a primary objective - to create change. They carried out their study sequentially. First they studied the prevalence of violence among women seeking health care by administering a questionnaire. They then conducted semi-structured telephone interviews with a sub-sample of those women, inquiring about what the experience of being asked questions about family violence in the healthcare setting was like and if it made a difference for them and/or their children. Both parts of the study were treated equally but separately. They had a shared primary objective but different research questions, different members of their team were primary investigators, the findings were presented as stand-alone studies, and submitted to different journals for publication.

\section{Sequential exemplar 3}

$$
\text { QUANT } \rightarrow \text { qual (integrated), }
$$$$
\text { summarised in Table } 4
$$

The title of Rumsey et al.'s (2004) article, Altered body image: Appearance-related concerns of people with visible disfigurement, does not indicate that it is a mixed methods study. Neither do the key words. From the title, the reader may wonder if it is an interpretive qualitative study. Although not directly stated, it is the abstract that situates the study firmly in the postpositivist paradigm with the qualitative component clearly secondary. The words that clue you in are 'establish extent and type of psychosocial needs' and 'little is known about levels of distress' (2004: 443); these are phenomena that can be measured and described with quantitative methods. The study used cross-sectional survey design followed by semi-structured interviews to 'generate further quantitative and qualitative data about individual concerns, and satisfaction with the provision of care' (2004: 443). This is a sequential mixed methods design in which the qualitative component complements the quantitative (QUANT $\rightarrow$ qual): statistical results are reported in text and in tables with various findings being echoed by the interview data (2004: 450).

\section{Concurrent mixed methods designs}

In the concurrent design, both methods are used at the same time. In some studies, both are of equal importance to answering the research question but, like sequential designs, most often

\section{Table 4: Sequential Exemplar 3: QUANT $\rightarrow$ qual (InTegrated)}

\begin{tabular}{ll} 
Rumsey & \\
et al. (2004) & Altered body image: Appearance-related concerns of people with visible disfigurement \\
\hline Design & - Cross-sectional survey followed by semi-structured interviews. \\
Comment & - Statistical results are reported in text/tables with findings being echoed by the interview data. \\
\hline
\end{tabular}


one set of findings is used to complement the other, e.g. QUAL + QUANT or QUANT + QUAL. Sometimes they are used in separate sub-studies, and the data is analysed separately and then compared together. This is the widely advocated triangulation method of data collection where one set of data is used to corroborate the findings from another. In other studies, one method is 'nested' (Creswell, 2003: 218) inside the other and is usually subordinate: QUANT + qual or QUAL + quant. The value of the secondary data set to the research is that it offers a broader perspective than the primary data could offer alone. However, difficulties arise when attempting to integrate the findings: the data sets are often not compatible for analysis and result 'in unequal evidence within a study' (Creswell 2003: 219). Commonly, the inequality produces a bias in favour of the quantitative data because of its concrete attributes - as 'hard' data, it is able to be represented in numbers and statistics. We have chosen as our exemplars a QUAL + QUANT and a QUANT + qual study as they raise interesting design issues that are important to consider when planning a concurrent mixed methods study. The QUANT + qual combination is the most commonly used mixed methods design in nursing research, the field from which we have drawn the exemplars.

\section{Concurrent exemplar 1}

$$
\text { QUAL + QUANT, summarised in Table } 5
$$

Somervell, Saylor and Mao's (2005) study illustrates the complementary nature of qualitative and quantitative methods. Their aim was twofold: to understand the needs of families who were attending court for drug dependency reasons, and to 'determine mothers' perception of PHN [Public Health Nurse] strategies that could help with the difficult task of reunifying with their children' (p. 61). Quantitative methods such as reviewing court files complemented the data gained through the qualitative methods of interviewing a group of mothers $(n=4)$ and observing mothers during court proceedings. Not too far into reading the paper, however, one becomes aware of paradigmatic dissonance the language simultaneously reflects positivist and interpretive positionings and there are evident contradictions. Which paradigm underpins the study? The paper's title, Public health nurse interventions for women in a dependency drug court, gives the first clue that the study's research paradigm is positivist/postpositivist. Its focus on interventions signals an assumption of cause and effect (determinism). This paradigmatic conclusion is supported on reading further:

1. A literature review is given followed by a description of a conceptual framework which positions the theoretical notions explored in the study (theory verification).

2. No reference is made to methodology (postpositivist positioning is not made explicit).

3. Throughout the paper women who were interviewed $(n=4)$ were referred to both as 'subjects' and 'participants' (lack of clarity as to researcher-researched relationship).

4. The women 'were asked the same questions

TABle 5: Concurrent Exemplar 1: QUAL + QUANT

\begin{tabular}{ll} 
Somervell et al. (2005) & Public health nurse interventions for women in a dependency drug court \\
Design & - Content analysis (reviewing files), interviewing and observation. \\
Comment & - Mix of methods enables a rich description of research topic. \\
& $\begin{array}{l}\text { - Dissonance between interpretivist and positivist positioning gives rise to } \\
\text { unacknowledged contradictions. }\end{array}$ \\
\hline
\end{tabular}


during the interview process' (p. 64) - (an attempt to control for bias and variability).

5. Although in the methods section reference was made to purposive sampling, in the conclusion the authors of the study noted that a limitation was that the women 'were not randomly selected' (p. 64) (would have enabled a more representative sample to ensure generalizability of the findings).

The study by Somervell et al. (2005) highlights some of the strengths of combining qualitative and quantitative methods (a broad focus and a variety of data collection approaches enables the gathering of rich descriptions of a phenomenon), but also some of the 'messiness' that can occur when the paradigmatic positioning is not acknowledged or clearly understood. The use of qualitative methods with a dusting of interpretive (qualitative) concepts in a research report do not make a positivist/scientific study inclusive of the interpretive paradigm (the 'best of both worlds'); rather the qualitative methods are used in the service of the scientific method. As demonstrated in Somervell et al. (2005) research report, if the paradigmatic assumptions are not made explicit, the ensuring analysis may contain contradictory statements that challenge the theoretical and methodological rigour of the research.

\section{Concurrent exemplar 2}

QUANT + qual (nestled), summarised in Table 6

The QUANT + qual nestled design used by Borjesson, Paperin and Lindell (2004) in their study of maternal support during the first year of infancy, is the classical mixed methods design. Used by health professionals since the 1950s the design consist of a survey questionnaire using measurable items to produce quantitative (hard) data with either some open-ended questions or a space for comments to enable the collection of qualitative (soft) data. Borjesson et al. (2004) questionnaire consisted of 37 items (demographic details, Likert scales and multiple choice questions) with space underneath each for respondents to write comments. An openended question asking for their views on society's contribution to supporting mothers in their parenting role was included at the end. The qualitative data was clearly being used to support the quantitative findings. This nestled positioning of the qualitative component of the study is evident too in the way the findings are presented; the quantitative results are given first with explanatory, descriptive, or supportive quotes from the respondents' written comments. Unlike the Somervell et al. (2005) study there was paradigmatic congruence. Although the methodology was not specifically named as descriptive mixed methods, its descriptive nature was consistent within and between each section as was the use of postpositivist language.

\section{Reflections on mixed methods typologies}

Our typology shares many similarities with Creswell's (2003). The major difference between our view and his arises around his categories of sequential and concurrent transformative mixed methods designs. The key feature of transformative designs according to Creswell is that they are underpinned by 'a theoretical perspective' (p. 216) that guides the research and is more important than the choice of methods. In our view all research is theoretically guided but, as we have said, it is common

TABle 6: Concurrent Exemplar 2: QUANT + oual (Nestled)

\begin{tabular}{ll} 
Borjesson et al. (2004) & Maternal support during the first year of infancy \\
\hline Design & - Survey questionnaire that includes quantitative and qualitative items. \\
Comment & - Qualitative data clearly used to support quantitative.
\end{tabular}


that positivists (including postpositivists) do not acknowledge this. For example, the positivist claim that there is an objective reality to be discovered is a theoretical claim about the nature of human perception and knowing. Creswell also takes the position that qualitative research is 'one distinct methodology' (p. 217); in contrast we understand there to be many distinctive methodologies that are qualitative and that these cross diverse paradigms. In our view, the idea of 'transformative' research points towards the radical/critical paradigm that is centrally concerned with producing research that will lead to social change (Grant \& Giddings 2002). Where we do agree with Creswell is in his argument that mixed methods research can be used not only for descriptive/explanatory research but also for transformative/critical work.

\section{CONCLUSION}

The increasing complexity of social and health care issues demands creative ways of investigating and finding solutions to myriad problems. In its various forms, mixed methods research is now accepted as valuable 'real world research' (Robson 2002) because it offers a versatility of approach. Moreover, it well suits the practical focus of researching nursing practice and clientcentred care. Although mixed methods research has been captured by postpositivism, it can be an effective approach for researchers from all paradigms.

\section{References}

Blaxter L, Hughes C and Tight M (2001) How to research, 2nd edn, Philadelphia PA, Open University Press.

Borjesson B, Paperin C and Lindell M (2004) Maternal support during the first year of infancy, Journal of Advanced Nursing 45(6): 588-594.

Creswell JW (2003) Research Design: Qualitative, Quantitative, and Mixed Methods Approaches (2nd edn), Thousand Oaks CA, Sage.

Giddings LS (2005) Mixed methods research:
Positivism dressed in drag? Journal of Research in Nursing 11(3): 195-203.

Grant BM and Giddings LS (2002) Making sense of methodologies: A paradigm framework for the novice researcher, Contemporary Nurse 13(1): 10-28.

Guba EG and Lincoln YS (1994) Competing paradigms in qualitative research, in: Denzin NK and Lincoln YS (Eds), Handbook of Qualitative Research, pp. 105-117, Thousand Oaks, CA, Sage.

Ironside P (2003) Trying something new: Implementing and evaluating narrative pedagogy using a multimethod approach, Nursing Education Perspectives 24(30): 122-128.

Koziol-McLain J, Gardiner J, Batty P, Rameka M, Fyfe E and Giddings LS (2004) Prevalence of intimate partner violence among women presenting to an urban adult and paediatric emergency care department, New Zealand Medical Journal 117(1206): U1174.

Miles MB and Huberman AM (1994) Qualitative Data Analysis: An Expanded Sourcebook, Thousand Oaks CA, Sage.

Patton MQ (2002) Qualitative Research and Evaluation Methods, 3rd edn, Thousand Oaks, CA, Sage.

Robson C (2002) RealWorld Research: A Resource for Social Scientists and Practitioner-Researchers, 2nd edn, Oxford, Blackwell Publishers.

Rumsey N, Clarke A, White P, Wyn-Williams M and Garlick W(2004) Altered body image: Appearance-related concerns of people with visible disfigurement, Journal of Advanced Nursing 48(5): 443-453.

Sarantakos S (1998) Social Research, 2nd edn, Basingstoke, Macmillan.

Somervell AM, Saylor C and Mao C (2005) Public health nurse interventions for women in a dependency drug court, Public Health Nursing 22(1): 59-64.

Tashakkori A and Teddlie C (Eds) (2003) Handbook of Mixed Methods in Social \& Behavioral Research, Thousand Oaks CA, Sage.

Wuest J, Merritt-Gray M and Ford-Gilboe M (2004) Regenerating family: Strengthening the emotional health of mothers and children in the context of intimate partner violence, Advances in Nursing Science 27(4): 257-274. 